\title{
Estimating heat losses in solar collectors by IR thermography and numerical simulations
}

\author{
by D. Dović, S. Švaić, A.Galović
}

University of Zagreb, Faculty of Mechanical Engineering and Naval Architecture, Zagreb, Croatia

\begin{abstract}
The paper demonstrates application of numerical methods supported by IR thermography for heat transfer evaluation in two types of plate solar collectors: with and without tubes. Numerical simulations of collector heat losses are performed in order to analyze influence of the welding between absorber plate and tubes on the collector efficiency. Results are compared with the collector thermal test data and IR measurements of absorber temperature field. The prototype of plate collector without tubes is investigated through numerical simulations of heat losses which are compared against the experimental values. A method for estimating the local heat transfer coefficients on the working fluid side in the prototype collector by means of IR thermography is presented and computed values compared against the experimental ones.
\end{abstract} plate

KEY WORDS: numerical simulations, IR thermography, solar collector, heat losses, efficiency, absorber

\section{Introduction}

In past two decades thermal performances of plate type solar collectors have been greatly improved, mainly due to the development of highly efficient absorber coatings and improved quality of the contact between tubes and absorber plate. As the optical properties of commercial selective coatings (absorbivity $a=0.95-0.97$, emissivity $\varepsilon=0.05-0.07$ ) do not leave much room for significant improvements, further increase of thermal performances could be achieved by increasing the transmittivity of the solar glass cover (presently $\tau=0.9 \div 0.91$ ) and by further enhancement of heat transfer between absorber plate and working fluid. In case of a plate collector with tubes it is important to ensure a good contact between the tubes and absorber plate, that is in a practice normally done by applying different types of welding or, alternatively, by special gluing procedures. The experimental results in [1] and [2] clearly showed that the increased size and consistency of the welding can lead to $30 \%$ improvement in the collector efficiency.

The purpose of the present research was to explore to which extent shape and dimensions of the welding between absorber and tube influence collector thermal performances. This has been accomplished by applying numerical simulations of collector heat losses, collector thermal output (and efficiency) measurements as well as by the thermographic measurements of absorber surface temperature which is directly coupled to the heat losses from absorber to surrounding.

\section{Solar collector efficiency}

The solar collector efficiency $\eta_{\text {coll }}$ (Eq. [1]) reflects the amount of heat losses from absorber plate to surrounding for a given solar radiation intensity $I_{\text {sun }}$ and temperature of fluid $t_{f}$ and surrounding air $t_{\text {air }}$ (figure 1 ).

$$
\eta_{\text {coll }}=\frac{Q_{\text {coll }}}{Q_{\text {sun }}}=\frac{Q_{\text {coll }}}{l_{\text {sun }} \cdot A_{\text {coll }}}
$$

where $Q_{\text {coll }}$ is the useful heat collected by collector and delivered to working fluid, $Q_{\text {sun }}$ is the total amount of irradiated solar energy $I_{\text {sun }}$ over the referent collector surface area $A_{\text {coll. }}$

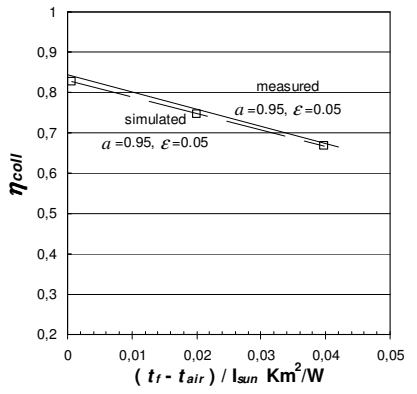

Fig. 1. Measured plate type collector efficiency, comparison with simulated values

These convective and radiative losses are smaller as higher is the heat transfer resistance from absorber to surrounding and more intensive is absorber plate cooling by working fluid. The heat transfer resistance from absorber to surrounding depends mainly on the coating emissivity factor $\varepsilon$ (which should be as low as possible) and the distance between cover glass and absorber (preferably 10-15 mm). Also, more effective is absorber 
cooling by working fluid - the absorber plate temperature will be lower and consequently the heat losses lower (and efficiency higher). Hence, the heat transfer resistance between plate and fluid in tubes should be as low as possible, which is mainly dependent upon shape and dimension of the welding between plate and tube as well as upon the conductivity of welding material.

\section{Numerical analysis of welding geometry}

The influence of welding geometry on the heat losses can be evaluated by means of numerical simulation of heat transfer from the heated absorber to the fluid passing throughout tubes, accounting simultaneously for the heat losses to surrounding air. Such numerical model is developed in the 2D domain for different welding geometry and provided here in terms of corresponding absorber temperature fields and efficiency curves. The simulations are performed in the numerical code FLUENT. Figures 2 and 3 show obtained temperature fields within the absorber plate, welding and tube for welding width $1.5 \mathrm{~mm}$ and $0.5 \mathrm{~mm}$, at the identical working parameters (radiation, temperature of fluid and surrounding). The model assumes that the welding is of consistent form and same conductivity as the absorber plate (cooper $\lambda=372 \mathrm{~W} /(\mathrm{mK})$ ) along the whole tube, which can be obtained by e.g. the laser welding technique. The computed temperature fields clearly show that the temperature gradient within the welding is higher in the case of welding width $0.5 \mathrm{~mm}$, reflecting larger heat transfer resistance which in turn leads to the higher absorber temperature and consequently lower collector efficiency. These results would suggest that the welding width should not be smaller than $1.5 \mathrm{~mm}$ for given welding geometry.

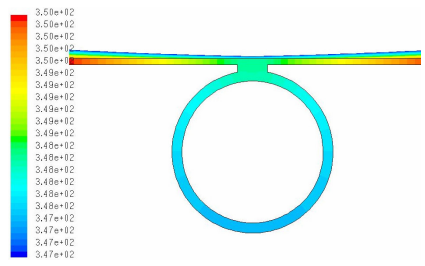

Fig. 2. Temperature profile in the absorber tube and welding of width $1.5 \mathrm{~mm}$

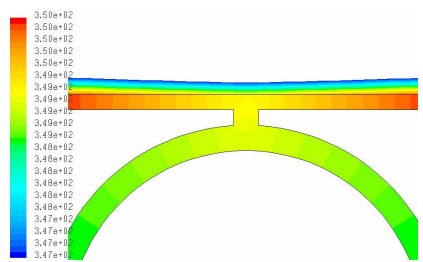

Fig. 3. Temperature profile in the absorber tube and welding of width $0.5 \mathrm{~mm}$

Results of simulation for the model with $1.5 \mathrm{~mm}$ welding are compared with the performed measurements on the solar collector of identical geometrical and optical properties. The comparison indicates fairly good agreement (within $4 \%$ ) between the numerical and test results (figure 1).

\section{IR thermography and absorber temperature}

The additional method employed in this research for inspection of intensity the absorber plate is cooled by working fluid is based on use of IR thermographic camera for recording a temperature field over the absorber plate, provided the collector top glazing has been removed before. Figure 4 shows the temperature profile of two unglazed plate collectors used as an evaporator in solar heat pump set up. At the left hand side collector the tubes are brazed to the absorber plate only in a few spots, while at the other collector the tubes are brazed continuously along their whole length. The recorded IR images clearly indicate places of the improperly formed contact between tubes and plate characterized by the increased temperature as well as an inefficiently cooled absorber plate side areas due to the given position and geometry of tube bank. The temperature profiles obtained by the simulation in FLUENT on 3D model (figure 5) also show increased absorber temperature at the places along the tube with no welding. The other, well brazed, collector operates at the lower average absorber temperature (figures 4 and 5) and consequently at higher measured efficiency. 


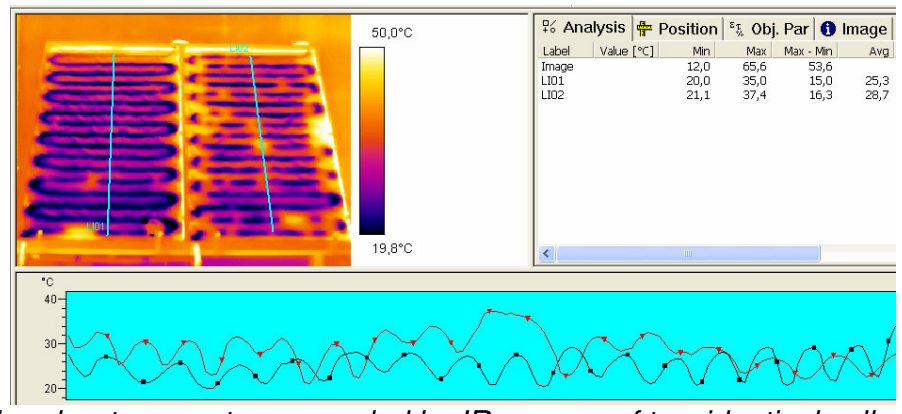

Fig. 4. Analysis of the absorber temperature recorded by IR camera of two identical collectors with different length of welding along tube bank

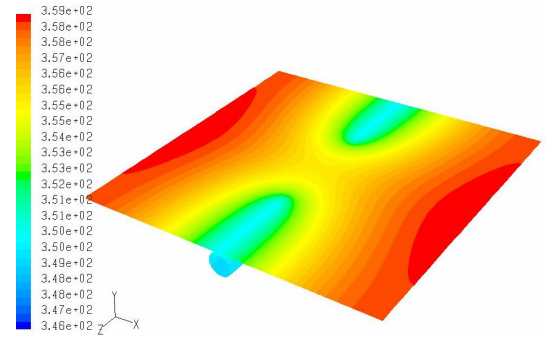

a)

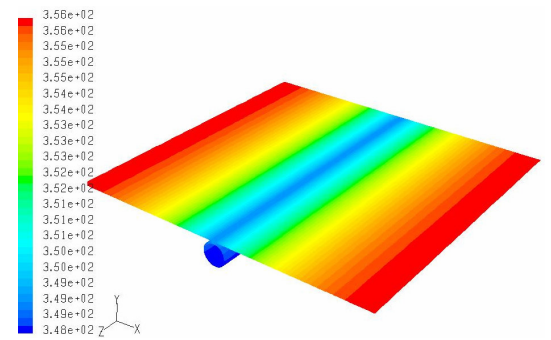

b)

Fig. 5. Numerically obtained temperature profile and efficiency for two repeating segments of unglazed absorber with partly (a) and fully (b) welded tubes to absorber plate, operating at the same conditions $\left(\left(t_{f}-t_{\text {air }}\right) / I_{\text {sun }}=\right.$ $\left.0,03982 \mathrm{Km}^{2} / \mathrm{W}\right)$

\section{Heat transfer in plate collector without tubes}

Separate tests and numerical simulations in 3D domain have been done for the prototype of plate collector without tubes (figures 6 and 7). Such a type of collector was developed by present authors with the aim of increasing the overall contact area between absorber plate and working fluid that should in turn enhance the heat transfer there, also avoiding at the same time problems with ensuring proper welding during a production process. The measured efficiency of prototype was up to $30 \%$ higher compared with the previously tested plate collector with tubes (figure 1$)$ which has better optical properties of the coating $(a=0.95, \varepsilon=0,05)$ and identical properties of the glazing $(\tau=0,9)$. The prototype consists of two corrugated steel plates identical to those used in semi-welded plate heat exchangers (PHEs) which form the flow channel divided from the other parts of plate by laser welding. The outer absorber plate is coated with the selective coating of $a=0.9$ and $\varepsilon=0.2$. Working fluid (water) flows in between plates from the inlet and outlet port (see figure 6). The other two ports are in PHEs normally reserved for the second fluid and separated from the flow channel by welding which prevents working fluid to flow there and properly cool this part of the absorber plate (high temperature areas $\sim 5^{\circ} \mathrm{C}$ around the inactive ports, figure 6).

Figure 7 shows the absorber temperature field measured by IR camera which is determined by using the referent values of the thermocouple attached on the outer side of $0.3 \mathrm{~mm}$ thick absorber plate. Local temperatures of the fluid flowing in between plates are determined by the thermocouples attached underneath the lower plate which is insulated on this side by the layer of $50 \mathrm{~mm}$ thick PU foam.

Using these data and measured collector thermal output $Q_{\text {coll, }}$ the local heat transfer coefficients on the working fluid side are calculated and compared with experimentally obtained ones ([3] and [4]) used in the simulations. The results are provided in Table 1.

Local heat transfer coefficient on fluid side is calculated according to

$$
\alpha_{f, \text { loc }}=\frac{Q_{\text {coll }}}{A_{\text {aps }} \cdot\left(t_{a b s}-t_{f}\right)}
$$

where $t_{a b s}$ is the local absorber temperature measured by IR camera and $t_{f}$ is the local fluid temperature measured by the thermocouple.

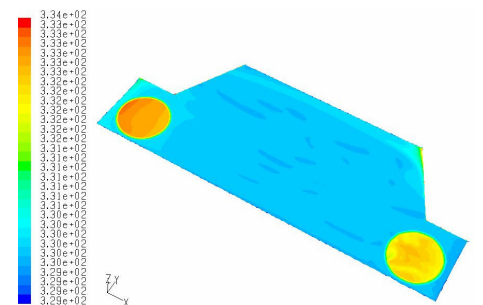

Fig. 6. Numerically obtained temperature field over the prototype's absorber plate, temp. scale in $K$ 

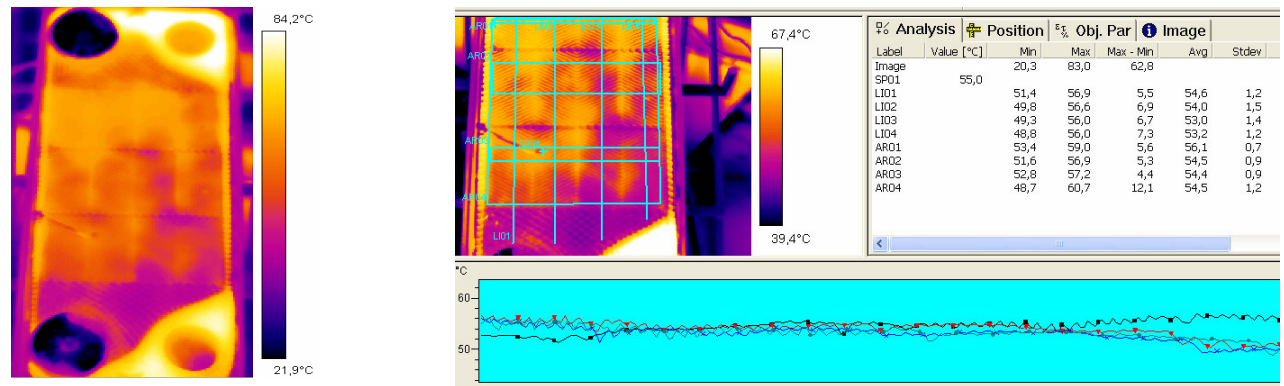

Fig. 7. IR image of tested prototype of plate collector without tubes provided together with the results of the analysis

Thermogram on figure 7 reveals areas which are more effectively cooled, indicating at the same time parts of the channel with higher velocities and/or more intensive heat transfer, such are the distribution triangle and right hand side of the plate.

Table 1. Temperatures of absorber and fluid provided together with the calculated values of the local heat transfer coefficient on working fluid side for the collector operating condition

\begin{tabular}{|l|l|l|l|l|l|l|}
\hline $\begin{array}{l}\mathrm{t}_{\mathrm{av}, \text { sim }} \\
{ }^{\circ} \mathrm{C}\end{array}$ & $\begin{array}{l}\mathrm{t}_{\mathrm{av}, \text { IC }} \\
{ }^{\circ} \mathrm{C}\end{array}$ & $\begin{array}{l}\mathrm{t}_{\text {out }} \\
{ }^{\circ} \mathrm{C}\end{array}$ & $\begin{array}{l}\mathrm{t}_{\mathrm{d}} \\
{ }^{\circ} \mathrm{C}\end{array}$ & $\begin{array}{l}\mathrm{t}_{\mathrm{s}} \\
{ }^{\circ} \mathrm{C}\end{array}$ & $\begin{array}{l}\mathrm{t}_{\mathrm{g}} \\
{ }^{\circ} \mathrm{C}\end{array}$ & themocouples \\
\hline $\begin{array}{l}\alpha_{f}, \mathrm{~W} /\left(\mathrm{m}^{2} \mathrm{~K}\right) \\
\text { (experimental) }\end{array}$ & 56,1 & 55 & 53,88 & 55,166 & 55,983 & \\
\hline 494.9 & & 55 & 56,9 & 57,8 & $\begin{array}{l}\mathrm{t}_{\text {abs,loc, }}{ }^{\circ} \mathrm{C} \\
(\text { from thermogram })\end{array}$ \\
\hline
\end{tabular}

$\mathrm{t}_{\text {out }}$ - temp. of the outer plate (absorber) measured by the thermocouple (spot SP01)

$t_{d}$ - temp. of the lower insulated plate i.e. working fluid measured by the thermocouple (below SP01)

$t_{s}$ - temp. of the lower insulated plate i.e. working fluid at a half distance between inlet/outlet ports, measured by the thermocouple (area AR02)

$\mathrm{t}_{\mathrm{g}}$ - temp. of the lower insulated plate i.e. working fluid at upper part of absorber measured by the thermocouple (area AR01)

$t_{a b s, \text { loc }}$ local temp. of the absorber above the spots corresponding to $t_{d}$, $t_{s}$ and $t_{g}$ obtained from the thermogram

$t_{a v, I C}$ - average temp. of the absorber obtained from the thermogram (area AR04)

$t_{a v, s i m}$ - average temp. of the absorber obtained from the simulation results

The average absorber temperature obtained from the thermogram on figure 7 is in fairly good agreement with the numerically obtained one (difference is $<0,3^{\circ} \mathrm{C}$ ). Unfortunately, a change in the absorber temperature as small as $0.2^{\circ} \mathrm{C}$ leads to $20 \%$ change of heat transfer coefficient in the analyzed case. This can explain the deviation of local heat transfer coefficient $( \pm 15-20 \%)$ determined by the thermogram from the experimentally obtained values [3,4].

\section{Conclusions}

Presented results of the numerical analysis on the influence of a welding form and dimensions on the collector efficiency suggest that the welding width should not be smaller than $1.5 \mathrm{~mm}$ and the welding material should be homogenous with high overall conductivity. This can be achieved by the laser welding technique used in tested collectors. IR thermography is successfully employed for detecting places of high heat resistance from the collector absorber to the tubes due to absence of welding and/or inhomogenous welding material there, which all manifests as hot spots on the absorber surface. The same local increase of temperature is evident in the numerically obtained temperature field of the plate collector with tubes. The plate type collector prototype without tubes, developed as an attempt to avoid problems with welding and to further decrease the heat transfer resistance to working fluid, is analyzed numerically and by thermography. Obtained average absorber temperatures agree well, while thermograms allowed for further more detailed inspection of the absorber plate cooling by working fluid, revealing the areas of flow maldistribution, lower velocities and/or less intensive heat transfer. Calculated values of local heat transfer coefficient on the fluid side differ from the experimentally obtained ones by max. $\pm 20 \%$.

Due to high sensitivity of the presented method for calculation of the heat transfer coefficient on small changes in the surface temperature, such a method requires accurate measurement of absorber and fluid temperatures. More reliable results could be achieved by increasing the difference between fluid and absorber temperature. 


\section{REFERENCES}

[1] D. Dović. Experimental and numerical study of collector with corrugated absorber, Doctoral thesis, University of Zagreb (2005)

[2] J.A. Duffie, W.A. Beckman. Solar engineering of thermal processes, John Willey\&Sons, New York (1991).

[3] A. Muley, R.M. Manglik. Experimental study of turbulent flow heat transfer and pressure drop in a plate heat exchanger with chevron plates, J. Heat Transfer, Transactions of the ASME, 121 (Feb. 1999) 110117.

[4] A. Muley, R.M. Manglik, H.M. Metwally. Enhanced heat transfer characteristics of viscous liquid flows in a chevron plate heat exchanger, J. Heat Transfer, Transactions of the ASME, 121 (Nov. 1999) 1011-1017.

[5] W.W. Focke, J. Zachariades, and J. Olivier. The effect of the corrugation inclination angle on the thermohydraulic performance of plate heat exchangers, Int. J. Heat and Mass Transfer, 28 (1985) 14691479.

[6] J. Twidell, T. Weir (1997) Renewable energy resources, E\&FN Spon, London.

[7] S. Kakac, Y. Yaman. Convective Heat Transfer, CRC Press, Boca Raton (1995). 
http://dx.doi.org/10.21611/qirt.2008.11_02_05 